\title{
Lymphoid Nodules in the Thymus of the Chicken
}

\author{
By \\ Kazuhiko Awaya, Susumu Tomonaga, \\ Kensuke Sakai and Junichi Tashiro \\ Department of Anatomy, Yamaguchi University \\ School of Medicine, Ube, Japan \\ - Received for Publication, March 8, 1975-
}

It is generally accepted that the thymus is one of the central lymphoid organs in the chicken and that lymphoid nodules are rarely seen in the thymus. Janković and his collaborators $(1967,1969)$ reported the presence of lymphoid nodules in the thymus of some chickens. We have made similar observation while studying the ontogeny of lymphoid organs in the chicken. This paper deals with the appearance of lymphoid nodules in the thymuses of normal chickens and chickens vaccinated with Newcastle disease.

\section{Materials and Methods}

The animals used in this work were the same chickens employed in a previous study (Nomura 1972, 1973). They included 79 embryos and 145 birds of various ages, from newly-hatched to 1-year-old. These animals were obtained from the Yoshiwa Chicken Farm in Ube city and the Nishinippon Chicken Farm in Hofu city during the period June 1966 to May 1967. Chickens older than 8 weeks had been injected with Newcastle vaccine 50 and 120 days after hatching. The thymuses, along with other lymphoid organs, were examined histologically. Lymphoid nodules were counted in at least 2 sections per organ.

\section{Results}

Lymphoid nodules were observed in the thymus of 9 out of 145 chickens (Table 1). They were not seen in the thymuses of embryos and of chickens younger than four weeks. Nodules first appeared 5 weeks after hatching and were localized in the medulla. They wero not seen elsewhere.

The lymphoid nodules were sharply circumscribed, round or oval structures and consisted of lymphocytes, cells in mitosis and reticulum 
Table 1. Incidence of lymphoid nodules in the thymus of the chicken.

\begin{tabular}{|c|c|c|c|}
\hline Age & $\begin{array}{c}\text { Total number } \\
\text { of animals }\end{array}$ & $\begin{array}{c}\text { Number with } \\
\text { lymphoid nodules }\end{array}$ & Percentage \\
\hline $\begin{array}{c}\text { Embryonic } \\
\text { 15-20 days }\end{array}$ & 79 & 0 & - \\
Postembryonic & & & \\
0.2 days-2 weeks & 15 & 0 & - \\
$3^{1}$-7 weeks & 25 & 3 & 12.0 \\
$8-17$ weeks $^{2)}$ & 50 & 1 & 2.0 \\
$18-52$ weeks $^{8)}$ & 55 & 5 & 9.0 \\
\hline Total & 224 & 9 & 4.0 \\
\hline
\end{tabular}

1) Chickens after completion of lymphocyte peripheralization (Nomura 1973).

2) Chickens vaccinated with Newcastle disease on day 50.

3) Chickens vaccinated with Newcastle disease on day 50 and 120.

cells (Figs. 1-4). They were devoid of a dark zone consisting of small lymphocytes, and were almost completely delimited from the surrounding parenchyma by a thin band of connective tissue. Occasionally, these lymphoid nodules were found adjacent to small blood vessels and capillaries. Not infrequently, island of epithelial cells and cystic structure lined with epithelial cells were seen nearby.

The number of lymphoid nodules in the individual thymuses of the 9 chickens in which they occurred was not constant. Table 2 lists the average number of nodules observed per tissue section of the whole of a thymic lobe. The thymuses of two birds (TORI 35 and 95) contained many nodules but the others had only 1 or a few. Even in those containing many nodules their number differed considerably from lobule to lobule (Table 2). No marked differences in the size of the nodules were noted.

Table 2. Average number of lymphoid nodules per section of thymus of the 9 animals listed on Table 1.

\begin{tabular}{|c|c|c|c|}
\hline $\begin{array}{c}\text { Animal } \\
\text { No. }\end{array}$ & $\begin{array}{c}\text { Age } \\
\text { (Weeks) }\end{array}$ & per lobe & per lobule \\
\hline TORI 22 & 5 & 1 & $0-1$ \\
TORI 30 & 6 & 2 & $0-2$ \\
TORI 35 & 7 & 13 & $0-5$ \\
TORI 49 & 10 & 2 & $0-2$ \\
TORI 95 & 19 & 12 & $0-6$ \\
TORI 96 & 20 & 4 & $0-2$ \\
TORI 103 & 22 & 1 & $0-1$ \\
TORI 104 & 22 & 2 & $0-2$ \\
TORI 119 & 30 & 1 & $0-1$ \\
\hline
\end{tabular}


Lymphoid nodules with similar cellular characteristics were also found in the spleen and in the tonsilla caecalis of these chickens. They first appeared 3 weeks after hatching in the spleen and 4 weeks after hatching in the tonsilla caecalis. Thus, lymphoid nodules in these two lymphoid organs developed earlier than in the thymus (Table 3). Lymphoid nodules could not be detected in any lymphoid organ, except the bursa of Fabricius, before the second week of life.

Table 3. Time of first appearance of lymphoid nodules and plasma cells in the various lymphoid organs of the chicken.

\begin{tabular}{|l|c|c|}
\hline \multicolumn{1}{|c|}{ Organs } & Lymphoid nodules & Plasma cells \\
\hline Bursa & $*$ & 1 Weeks \\
Thymus & 5 Weeks & 8 Weeks \\
Spleen & 3 Weeks & 3 Weeks \\
Tonsilla caecalis & 4 Weeks & 4 Weeks \\
\hline
\end{tabular}

* Bursal lymphoid nodules were present prior to hatching.

The thymuses also contained a few plasma cells in chickens older than 8 weeks. The time of initial appearance of this type of cell in the various lymphoid organs, including the bursa, is shown in Table 3.

\section{Discussion}

The principal findings shown by the present study concern the presence of lymphoid nodules in the thymus of some chickens during the course of normal growth. The appearance of a few plasma cells was also a normal feature of the thymus in chickens after 8 weeks of age. The development of lymphoid nodules and plasma cells has been noted to be closely related to antigenic stimulation. The present results, therefore, suggest that the thymus, in certain circumstances, responds to direct contact with the antigen with resultant production of such thymic lymphoid nodules.

Thymic lymphoid nodules have been reported in guinea pigs (Marshall and White 1961, Awaya 1965) and in hamsters (Sherman et al. 1964, 1965) rollowing direct injection of antigens into the thymus. Such nodules have not usually been observed following systemic administration of antigen. These findings suggest the presence of a "thymic barrier" preventing the entrance of the antigen into the thymic parenchyma. Sainte-Marie (1963) and Kostowiecki (1967), however, showed that soluble antigen or trypan blue, injected intramediastinally or subcutaneously, penetrates readily into the thymic parenchyma. Other authors confirmed that there is no absolute barrier in 
the thymus (Clark 1964, Gervin and Holtzman 1972, Kouvalainen and Gitlin 1967, Kramersky et al. 1967, Raviola and Karnovsky 1972). Our data agree with these findings.

In the present study, the 6 chickens older than 8 weeks which had been injected with Newcastle vaccine, may have developed thymic lymphoid nodules because of this vaccination. But 3 chickens, aged 5 to 7 weeks, also had such structures in their thymuses without any specific antigen injection. These chickens may have been exposed to antigens normally occurring in their environment. Thus, the present study suggests that, occasionally, the thymus may participate directly in immune responses.

It is important to note that lymphoid nodules in the thymus first appeared at five weeks of age and that no other lymphoid organs, except the bursa of Fabricius, developed lymphoid nodules earlier than the 2nd week of life. The bursa reaches its maximum weight, relative to body weight, at that time (Nomura 1973). This supports the view that in the chicken lymphoid nodules are bursa-dependent (Cooper et al. 1965, 1966, 1967).

The thymic lymphoid nodules were localized in the medulla and often occurred near epithelial structures, suggesting that epithelial elements may have some relation to the formation of lymphoid nodules. Sherman et al. (1965) suggested that Hassall's corpuscles play a role in the formation of thymic lymphoid nodules, but our results shed no new light on this possibility.

\section{Summary}

Lymphoid nodules were found in the thymus of 9 out of 145 chickens during the course of normal growth. Nodules first appeared in the 5th week of life. Histologically these nodules consisted of lymphocytes of various sizes, cells in mitosis and reticulum cells. They closely resembled lymphoid nodules in the spleen and the tonsilla caecalis.

The possibility is discussed that the formation of lymphoid nodules in the thymus of the chicken is bursa-dependent and that the appearance of such thymic nodules may represent a close relationship to immune responses.

\section{References}

Awaya, K.: Secondary nodules of the thymus (Japanese). Saishin-Igaku 20: 26672676, 1965.

Clark, S.L.: The penetration of proteins and colloidal materials into the thymus from the blood stream. In: The Thymus, The Wistar Institute Symposium Monograph No. 2. Defendi, V. and Metcalf, D. (eds.) pp. 9-32, 1964. 
Cooper, M.D., Peterson, R.D.A. and Good, R.A.: Delineation of the thymic and bursal lymphoid systems in the chicken. Nature 205: 143-146, 1965.

Cooper, M.D., Peterson, R.D.A., South, M.A. and Good, R.A.: The functions of the thymus system and the bursa system in the chicken. J. exp. Med. 123: 75-102, 1966.

Cooper, M.D., Gabrielsen, A.E., Peterson, P.D.A. and Good, R.A.: Ontogenic development of the germinal centers and their function-Relationship to the bursa of Fabricius. In : Cottier, H., Odartchenko, N., Schindler, R. and Congdon, C.C. (eds.), Germinal Centers in Immune Responses. pp. 28-35, New York SpringerVerlag, 1967.

Gervin, S.W. and Holtzman, E.: The fate of exogenous peroxidase in the thymus of newborn and young adult mice. J. histochem. cytochem. 20:445-462, 1972.

Kostowiecki, M.: Does the poor immunological reactivity of the thymus really depend on the vascular barrier of Marshall and White? $Z$. mikr. anat. Forsch. 76 : 320-352, 1967.

Kouvalainen, K. and Gitlin, D. : Passage of antigens across the vascular barrier of the thymus. Nature $214: 592-593,1967$.

Kramarsky, B., Siegler, R. and Rich, M. A.: Presence of endothelial fenestrations in thymic capillaries of mice. J. Cell Biol. 35: 464-467, 1967.

Isaković, K. and Janković, B. D.: Germinal centers and plasma cells in the thymus of the chicken. In: Cottier, H., Odartchenko, N., Schindler, R. and Congdon, C.C. (eds.), Germinal Centers in Immune Responses. pp. 379-385, New York, Springer-Verlag, 1967.

Janković, B. D., Isaković, K. and Vujić, D. : Germinal center formation and antibody production in chickens grafted in ovo with allogeneic thymus, bursa and spleen. In : Fiore-Donati, L. and Hanna, M. G. Jr., (eds.), Lymphatic Tissue and Germinal Centers in Immune Response. pp. 269-276, New York, Plenum Press, 1969.

Marshall, A.H.E. and White, R. G.: The immunological reactivity of the thymus. Brit. J. exp. Pathol. 42: 379-385, 1961.

Nomura, A.: Ontogeny of the thymo-lymphatic tissues in the domestic fowls. 1 . Age change in organ weight (Japanese with English abstract). Igaku Kenkyu (Acta Medica) 42: 167-174, 1972.

Nomura, A.: Ontogeny of the thymo-lymphatic tissues in the domestic fowls. 2 . Histogenesis (Japanese with English abstract). Igaku Kenkyu (Acta Medica) 43 : 1-18, 1973.

Raviola, E. and Karnovsky, M. J. : Evidence for a blood-thymus barrier using electronopaque tracers. J. Exp. Med. $136: 466-498,1972$.

Sainte-Marie, G.: Antigen penetration into the thymus. J. Immunol. 91: 840-845, 1963.

Sherman, J.D., Adner, M.M. and Dameshek, W.: Direct injection of the thymus with antigenic substances. Proc. Soc. exp. Biol. \& Med. 115: 866-870, 1964.

Sherman, J.D., Adner, M. M. and Dameshek, W.: Experimental production of germinal follicles in the thymus. Relationship of Hassall's corpuscles to germinal follicle formation. Ann. New York Acad. Sci. 124 : 105-117, 1965. 


\section{Explanation of Figures}

\section{Plate I}

Figs. 1-4. Lymphoid nodules in the thymus of 4 chickens, aged 5 to 30 weeks. All magnifications $\times 400$.

Fig. 1. 5 weeks. Animal No. TORI 22.

Fig. 2. 19 weeks. Animal No. TORI 95.

Fig. 3. 20 weeks. Animal No. TORI 96 .

Fig. 4. 30 weeks. Animal No. TORI 119. 
Plate I
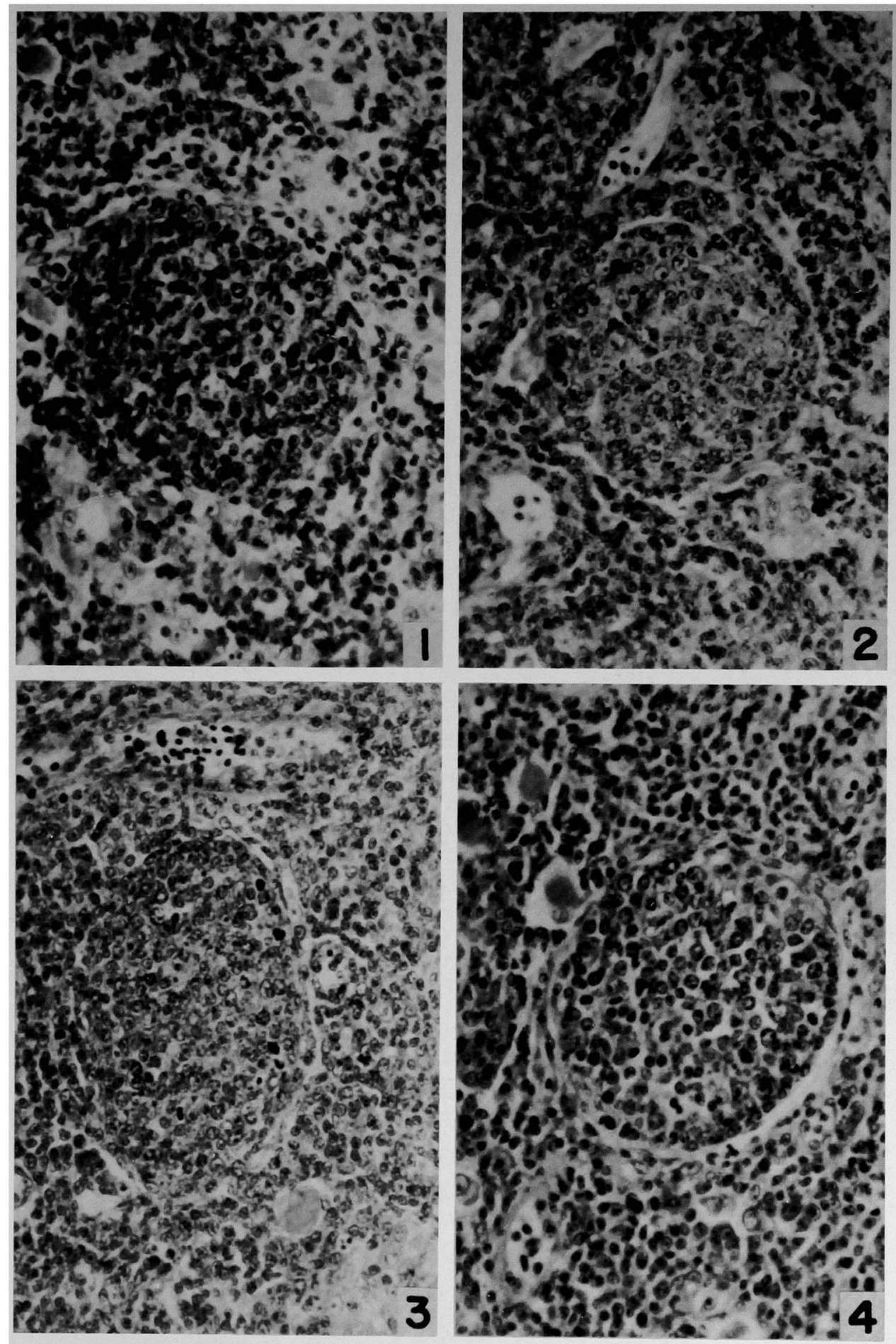

K. Awaya et al. 